\title{
Satisfaction With Knee Function After Primary Anterior Cruciate Ligament Reconstruction Is Associated With Self-Efficacy, Quality of Life, and Returning to the Preinjury Physical Activity
}

Clare Ardern, Annika Österberg, Sofi Sonesson, Håkan Gauffin, Kate E. Webster and Joanna Kvist

\author{
Journal Article
}

\section{Tweet}

N.B.: When citing this work, cite the original article.

Original Publication:

Clare Ardern, Annika Österberg, Sofi Sonesson, Håkan Gauffin, Kate E. Webster and Joanna Kvist, Satisfaction With Knee Function After Primary Anterior Cruciate Ligament Reconstruction Is Associated With Self-Efficacy, Quality of Life, and Returning to the Preinjury Physical Activity, Arthroscopy, 2016. 32(8), pp.1631-+.

http://dx.doi.org/10.1016/j.arthro.2016.01.035

Copyright: WB Saunders

http://www.elsevier.com/

Postprint available at: Linköping University Electronic Press

http://urn.kb.se/resolve?urn=urn:nbn:se:liu:diva-131910 


\title{
Satisfaction with knee function following primary anterior cruciate ligament reconstruction is associated with self-efficacy, quality of life and returning to the pre-injury physical activity
}

\begin{abstract}
Purpose: To assess whether patient-reported outcomes (psychological factors, appraisals of knee function and physical activity participation) were associated with satisfaction with knee function after anterior cruciate ligament (ACL) reconstruction.
\end{abstract}

Methods: Participants who were aged 18 to 45 years and a minimum 12 months post-primary ACL reconstruction completed a questionnaire battery evaluating knee self-efficacy, knee-related quality of life, self-reported function, and physical activity participation. Participants' responses to the question: "If you were to spend the rest of your life with your knee just the way it has been in the last week, would you feel... (7-point ordinal scale; 1 = happy, 7 = unhappy)" were categorised as satisfied, mostly satisfied or dissatisfied, and used as the primary outcome. Ordinal regression was used to examine associations between independent variables and the primary outcome.

Results: 177 participants were included at an average of 3 years after primary ACL reconstruction. At follow up, $44 \%$ reported they would be satisfied, $28 \%$ mostly satisfied and $28 \%$ dissatisfied with the outcome of ACL reconstruction. There were significant differences in psychological responses and appraisal of knee function between the three groups $(P<0.01)$, and significantly more people in the satisfied group had returned to their pre-injury activity (58\%) compared to the mostly satisfied (28\%) and dissatisfied $(26 \%)$ groups $(P<0.001)$. Multivariable analysis demonstrated that the odds of being satisfied increased by a factor of 3 with higher self-efficacy, greater knee-related quality of life, and returning to the pre-injury activity.

Conclusions: People who had returned to their pre-injury physical activity, and reported higher kneerelated self-efficacy and quality of life were more likely to be satisfied with the outcome of ACL reconstruction.

Level of evidence: Level IV, prognostic case series

Keywords: ACL, knee ligaments, patient-reported outcomes, self-efficacy, quality of life, physical activity 
Recently, effusion, giving way, thigh muscle strength symmetry, return to sport, and patient-reported function achieved consensus among clinicians as key criteria for evaluating successful outcome following treatment for anterior cruciate ligament (ACL) injury. ${ }^{1}$ Implicit in these criteria is the expectation that if they are achieved, patients will be satisfied with the outcome of their ACL reconstruction. Yet, there are differences in clinicians' and patients' rating of post-operative knee function, instability, confidence and physical activity participation. ${ }^{2}$ Therefore, patient satisfaction could be associated with factors other than what clinicians consider important.

It has been argued that the success of any medical intervention should be judged according to patients' perceptions of benefits gained from the treatment. ${ }^{3}$ Yet health research has focused on evaluating patients' satisfaction with the treatment received and the health services providing the treatment. ${ }^{6}$ Less attention has been paid to evaluating satisfaction with the outcomes of treatment. ${ }^{6}$

There is limited research examining satisfaction after ACL reconstruction, although knee symptoms (swelling, stiffness and laxity), and non-resumption of the pre-injury or desired physical activity have been associated with dissatisfaction. ${ }^{789}$ The association between satisfaction and patients' ratings of their knee symptoms and function is stronger than the association between satisfaction and objectively measured knee function. ${ }^{78}$ This suggests that patient-reported outcomes may be key influences on satisfaction.

The purpose of this study was to assess whether patient-reported outcomes (psychological factors and appraisals of knee function and physical activity participation) were associated with satisfaction with knee function after ACL reconstruction. We hypothesised that positive psychological responses and appraisals of knee function, and returning to the pre-injury activity would be associated with satisfaction following ACL reconstruction.

\section{Method}

This cross-sectional study was approved by the Regional Ethics Committee. Participants provided written informed consent to participate.

To identify potential participants, the medical records of patients who presented to one of two orthopaedic units in southeastern Sweden between January 2004 and December 2008 were reviewed. The inclusion criteria were: age 18-45 years at the time of the medical record review; minimum 12 months after primary ACL reconstruction. Exclusion criteria were: non-operative treatment; partial ACL tear; bilateral ACL injury; associated ligament pathology that required surgical treatment at the time of the index surgery; Outerbridge ${ }^{15}$ grade III or IV chondral injury; revision ACL reconstruction. All eligible participants were sent a questionnaire booklet that was designed to take approximately 30 minutes to complete. Up to three reminders were sent over a 6-week period to participants who did not respond. None of the participants were in receipt of worker's compensation for their injury. The questionnaire booklet comprised a battery of validated, knee-specific, patient-reported outcomes. Details of the scoring and measurement properties of each outcome are provided in Supplementary Appendix A.

\section{Outcome measures}

The primary outcome was satisfaction with knee function, measured with the question: "If you were to spend the rest of your life with your knee function just the way it has been in the last week, would you feel..." The response options were happy, satisfied, mostly satisfied, mixed feelings, mostly dissatisfied, dissatisfied, and unhappy. ${ }^{16}$ This question has been used in previous research to investigate patient satisfaction with the outcome of treatment for neck, low back and pelvic pain. ${ }^{16-18}$

The independent explanatory variables assessed for this study are detailed in Table 1. Variables were grouped as psychological factors, appraisals of knee function, and return to the pre-injury activity. 


\section{Data analysis}

SPSS 22 (IBM Corp, Armonk NY) was used for all data analysis. Responses to the primary outcome were classified into three groups for the analysis: satisfied (responded as "happy" or "satisfied"); mostly satisfied (responded as "mostly satisfied"); and dissatisfied (responded as "mixed feelings", "mostly dissatisfied", "dissatisfied" or "unhappy"). A listwise deletion approach was used to handle any missing data. Demographic data and univariate between-groups comparisons. Descriptive statistics were calculated for all variables. Comparisons between the satisfied, mostly satisfied and dissatisfied groups were made using one-way analysis of variance (ANOVA) with Games-Howell post hoc tests, and Chi-square tests as appropriate. The significance level was set to $\mathrm{P} \leq 0.05$.

\section{Relationships between patient satisfaction and independent explanatory variables (patient-reported outcomes)}

Proportional odds ordinal regression analysis was used to examine relationships between the dependent variable (patient satisfaction) and the independent explanatory variables (psychological factors, appraisal of knee function, and return to pre-injury activity). Multicollinearity was assessed using linear regression. ${ }^{26}$ The stepwise procedure used to identify the variables that were included in the final model is detailed in Supplementary Appendix B. The independent variables entered into the final regression model were: knee self-efficacy (K-SES), knee symptoms (KOOS_symptoms), kneerelated quality of life (KOOS_QoL), return to pre-injury activity, age, sex, and time to follow-up.Final model fit was assessed by determining the number of correctly predicted cases for each outcome category (satisfied, mostly satisfied, dissatisfied). The statistical assumptions for ordinal regression were assessed using a full likelihood ratio test, and binomial logistic regressions.

\section{Results}

In total 1447 medical records were reviewed, and 182 people (59\% of 308) completed the questionnaire booklet. Of these, 8 people who were inactive prior to their ACL injury and 4 who did not complete the question that was used as the primary outcome were excluded to ensure a homogeneous and representative sample. Data from 170 participants were included in the final analysis (Figure 1).

\section{Demographic characteristics}

There were 100 men (median age 28 years) and 70 women (median age 24 years) who participated at an average of 3 years (range 1 to 7 years) after ACL reconstruction. The majority were playing subelite competitive sport prior to their ACL injury $(n=106,62 \%) ; 40(24 \%)$ participated in active recreation activities such as recreational football, jogging or aerobics; $22(16 \%)$ played elite sport. The most common activities participated in prior to ACL injury were football $(n=84,49 \%)$, floorball $(n=19,11 \%)$, and handball $(n=9,5 \%)$, reflecting the typical distribution of sports played at the time of ACL injury in Sweden. ${ }^{27}$ Regarding satisfaction with knee function, the largest proportion of participants $(n=74,44 \%$ of 170$)$ reported they would be happy $(n=32)$ or satisfied $(n=42)$ if they were to spend the rest of their life with their knee function the way it had been over the previous week (Table 2). Therefore, for the subsequent analyses, the satisfied group comprised 74 participants, the mostly satisfied group comprised 49 participants, and the dissatisfied group comprised 47 participants (Table 2).

\section{Between-group comparisons}

The satisfied group was followed up significantly later (41 months) compared to the mostly satisfied (31 months) and dissatisfied (32 months) groups (Table 3). The satisfied group was also significantly older than the dissatisfied group. There were no other between-group differences in demographic factors (Table 3). 
There were statistical differences between the three groups for all measures of psychological factors and appraisals of knee function (Table 3). The satisfied group reported significantly more positive psychological responses and appraised their knee function as significantly better than the mostly satisfied and dissatisfied groups. The mostly satisfied group reported significantly more positive psychological responses and appraised their knee function as significantly better than the dissatisfied group (Table 3). The satisfied group had a higher rate of return to their pre-injury sport or recreational activity (61\% compared to $29 \%$ and $22 \%$, respectively) compared to the mostly satisfied and dissatisfied groups (Table 3).

\section{Relationships between patient satisfaction and independent explanatory variables (patient-} reported outcomes)

The assumptions for ordinal regression were met $\left(X_{(6)}^{2}=1.48, p=0.96\right)$. Knee self-efficacy, kneerelated quality of life (measured with the KOOS), and returning to the pre-injury activity, were significantly associated with satisfaction with knee function after ACL reconstruction $\left(X^{2}{ }_{(7)}=123.6, p\right.$ $<0.0001$ ) (Table 4). The number of correctly predicted cases for each of the three outcome categories were: satisfied, $71.4 \%$; mostly satisfied, $52.3 \%$; dissatisfied, $83.8 \%$.

For every one point increase in self-efficacy the odds of being mostly satisfied (compared to dissatisfied), or satisfied (compared to mostly satisfied) increased by $50 \%$ (odd ratio, $95 \% \mathrm{CI}=1.50$, 1.11-2.03) (Table 4). For every one-point increase in knee-related quality of life (KOOS_QoL) the odds of being mostly satisfied (compared to dissatisfied), or satisfied (compared to mostly satisfied) increased by $5 \%$ (odds ratio, $95 \% \mathrm{CI}=1.05,1.02-1.08$ ) (Table 4 ). Compared to those who had not returned to their pre-injury activity, participants who had returned to their pre-injury activity had 3 times increased odds of being mostly satisfied (compared to dissatisfied) or satisfied (compared to mostly satisfied) (odds ratio, 95\% CI $=3.30,1.51-7.24$ ).

\section{Discussion}

The main finding was that being satisfied with knee function after ACL reconstruction was associated with higher knee-related self-efficacy and quality of life, and returning to the pre-injury physical activity. In addition, less than half of people reported that they were satisfied with their knee function after surgery. This suggests that psychological factors, appraisal of knee function, and functional recovery may be important for satisfaction after ACL reconstruction.

Clinicians and patients may have differing views regarding what defines successful outcome after ACL reconstruction; ${ }^{2}$ and it is conceivable that satisfaction could be more strongly related to how patients view the success of their surgery. Therefore, the results of our study may give some indications about how patients define successful ACL reconstruction. Factors associated with satisfaction may represent proxies for how patients assess success. Although, patients may have come to be satisfied with their knee over time regardless of whether surgery restored knee function to their original expectations. Consensus among expert clinicians is that a constellation of impairment, activity and participation outcomes should be considered to determine the success of surgery. ${ }^{1}$ Participation-based outcomes such as return to sport may also be important considerations because they are likely important to patients. Our results suggest that returning to participation in the preinjury physical activity is important for satisfaction, adding support to the argument for measuring participation-based outcomes. However, the results also suggest that whether or not they return to the pre-injury activity it is not the only important factor for patients. Factors relating to an individual's perceptions of his or her knee function in all aspects of their life may also be important considerations.

Perceptions of knee function and the risks associated with participating may influence participation in physical activity after ACL reconstruction, irrespective of objective function. In our study, the less satisfied an individual was, the lower their self-efficacy and confidence, and the higher their fear for 
re-injury. Self-efficacy relates to an individual's perceptions of their own ability to reach a goal, and is influenced by emotions and experiences. ${ }^{28}$ An individual's perception of the threat inherent in a situation or event, and their own capability to cope with environmental factors is proposed to influence recovery from injury. ${ }^{29}$ Those who were more dissatisfied may have perceived the need to be more cautious and make allowances for their knee, or appraised that their knee was less likely to be able to withstand the demands of the activities they wanted to participate in. The fact that self-efficacy was the only significant psychological factor in the multivariable model may highlight its clinical importance. Perhaps an important question to ask patients is: can you do all that you want to be able to do without having to make allowances for your knee?

Given that psychological factors distinguished between the three groups in the univariate and multivariable analyses, we hypothesise that interventions aimed at addressing psychological factors might improve satisfaction after ACL reconstruction. However, prospective longitudinal studies are required to confirm this hypothesis. Since psychological factors are potentially modifiable, appropriate intervention during recovery and rehabilitation after surgery may improve patient satisfaction. The regression model suggested that self-efficacy might be the most important psychological factor for satisfaction after surgery. Examples of interventions that could have a positive impact on self-efficacy may include goal setting, imagery and modeling. ${ }^{30}$ Appropriate psychological interventions may also be an important for secondary ACL injury prevention. While those in the dissatisfied group had low knee self-efficacy, confidence and knee-related quality of life, and high fear of re-injury, over one quarter had returned to their pre-injury activity. Negative psychological responses have been associated with an increased risk of athletic injury. ${ }^{31}$

Historically, returning to the pre-injury level sport has represented a 'gold standard' outcome after ACL reconstruction. Yet, in our study, $39 \%$ of those in the satisfied group had not returned to their pre-injury activity. Among this sub-group who had not returned, half played competitive sport prior to their ACL injury. Therefore, even though returning to the pre-injury activity was significant in the multivariable model, there remained a sizeable proportion of people who reported being satisfied despite not returning to their pre-injury activity. In addition, $20 \%$ of those in the dissatisfied group had returned to their pre-injury activity. Taken together, the discordance between patient satisfaction and returning to the pre-injury activity may suggest that imposing a generic definition of successful outcome may be difficult; that success is better defined by the individual. Recent studies have highlighted the potential impact of contextual factors (including social and lifestyle-related factors) on returning to the pre-injury sport, ${ }^{32-36}$ and that many people do not return to their pre-injury sport following surgery. ${ }^{32}$ People choose to participate or cease participating for many reasons that may have nothing to do with their knee. ${ }^{37}$ People may also change their sports participation following surgery on the advice of their treating clinician. These reasons may help to explain relationships between sports participation and satisfaction.

Our results suggest that people who change or cease participation in their pre-injury activity can be satisfied with their knee function after ACL reconstruction. Activity modification may be an important secondary injury prevention strategy, particularly for patients who played pivoting sports prior to ACL injury. Returning to pivoting sports is a risk factor for a subsequent ACL injury. ${ }^{38}$ Return to pivoting sports also conceivably increases the risk of subsequent meniscal and chondral injury, ${ }^{39}$ and as a consequence, may predispose the knee to post-traumatic osteoarthritis. ${ }^{40}$ Therefore, the fact that patients can be satisfied despite not returning to their pre-injury activity could have important implications for clinicians and patients engaging in shared decision-making ${ }^{41}$ regarding return to play.

\section{Limitations}

We excluded patients who were inactive prior to their ACL injury to ensure our sample was representative of patients who have ACL reconstruction in Sweden. ${ }^{27}$ However, it is possible that our results are not generalizable to all patients with ACL injury, particularly if they were not physically active before injury. There may be other factors, ${ }^{42}$ including general mental health, not measured in 
our study that could also impact on satisfaction. In addition, it is possible that poor surgery or poor objective outcome could negatively influence patients' satisfaction after ACL reconstruction. We did not include an objective evaluation of knee function or stability because the focus of our study was on patient-reported outcomes. ${ }^{43}$ There is a stronger relationship between patients' assessments of knee symptoms and function and their satisfaction after surgery than objective measures of knee function and satisfaction. ${ }^{78}$ Nevertheless, future prospective studies could investigate the relative contribution of objective knee function to patient satisfaction after ACL reconstruction.

The cross-sectional design of our study meant that we did not assess participants' pre-operative expectations. The extent to which expectations are met may be a key determinant of satisfaction. ${ }^{44}$ In addition, we cannot determine whether more positive psychological responses and appraisal of knee function predict satisfaction. Therefore, future prospective studies that evaluate the relationships between expectations and satisfaction after ACL reconstruction may be warranted.

The question used as the primary outcome has not been validated in an ACL reconstruction population. However, in our study, people who scored high for satisfaction with knee function also rated their satisfaction with current knee function as high on a 10-point continuous scale (mean 8 points for satisfied group, 6 points for mostly satisfied group, 3 points for dissatisfied group; $p<$ 0.0001 ; data not included in the current analysis), suggesting preliminary evidence of the construct validity of our primary outcome. Those in the satisfied group were followed up significantly later (41 months) than those in the mostly satisfied (31 months) and dissatisfied (32 months) groups. It is conceivable that people who were followed up later may have had more time to recover optimal knee function, return to sport, test their knee in a broader range of desired activities, and adapt their participation in response to their knee impairment; and that this contributed to their appraisal of knee function and self-efficacy. Finally, only $59 \%$ of potential participants completed the questionnaire booklet. It is possible that non-responders had different psychological responses and appraisals of knee function, and different satisfaction with knee function after surgery. However, a response rate of $50 \%$ is the minimum suggested to reduce response bias. ${ }^{45}$

\section{Conclusion}

People who had returned to their pre-injury physical activity, and reported higher knee-related selfefficacy and quality of life were more likely to be satisfied with the outcome of ACL reconstruction.

\section{References}

1. Lynch A, Logerstedt D, Grindem H, et al. Consensus criteria for defining 'successful outcome' after ACL injury and reconstruction: A Delaware-Oslo ACL cohort investigation. Br J Sports Med 2013;10.1136/bjsports-2013-092299.

2. Roos E. Outcome after anterior cruciate ligament reconstruction - a comparison of patients' and surgeons' assessments. Scand J Med Sci Sports 2001;11:287-91.

3. Mannion A, Junge A, Elfering A, et al. Great Expectations. Really the novel predictor of outcome after spinal surgery? Spine 2009;34:1590-99.

4. Donabedian A. The quality of care. How can it be assessed? JAMA 1988;260:1743-48.

5. Sitzia J, Wood N. Patient satisfaction: A review of issues and concepts. Soc Sci Med 1997;45:1829-43.

6. Dawn A, Lee P. Patient expectations for medical and surgical care: A review of the literature and applications to ophthalmology. Surv Opthalmol 2004;49:513-24.

7. Kocher M, Steadman J, Briggs K, et al. Determinants of patient satisfaction with outcome after anterior cruciate ligament reconstruction. J Bone Joint Surg Am 2002;84-A:1560-72.

8. Schmale G, Kweon C, Larson R, et al. High satisfaction yet decreased activity 4 years after transphyseal ACL reconstruction. Clin Orthop Relat Res 2014;472:2168-74.

9. Graham J, Turner P, Johnson D. The patient's and surgeon's view of anterior cruciate ligament reconstruction - match or mismatch? J Bone Joint Surg Br 2004;86-B(Supp IV):440-41. 
10. Hudak P, Hogg-Johnson S, Bombardier C, et al. Testing a new theory of patient satisfaction with treatment outcome. Med Care 2004;42:726-39.

11. Woolley F, Kane R, Hughes C, et al. The effects of doctor-patient communication on satisfaction and outcome of care. Soc Sci Med 1978;12:123-28.

12. Ardern C, Taylor N, Feller J, et al. A systematic review of the psychological factors associated with returning to sport following injury. Br J Sports Med 2013;47:1120-26.

13. Czuppon S, Racette B, Klein S, et al. Variables associated with return to sport following anterior cruciate ligament reconstruction: A systematic review. Br J Sports Med 2014;48:356-64.

14. Everhart J, Best T, Flanigan D. Psychological predictors of anterior cruciate ligament reconstruction outcomes: a systematic review. Knee Surg Sports Traumatol Arthrosc 2013;10.1007/s00167-013-26991.

15. Outerbridge R. The etiology of chondromalacia patellae. J Bone Joint Surg Br 1961;43-B:752-57.

16. Cherkin D, Deyo R, Street J, et al. Predicting poor outcomes for back pain seen in primary care using patients' own criteria. Spine 1996;21(2900-2907).

17. Gutke A, Sjödahl J, Öberg B. Specific muscle stabilizing as home exercises for persistent pelvic girdle pain after pregnancy: a randomized, controlled clinical trial. J Rehabil Med 2010;42:929-35.

18. Wibault J, Öberg B, Dedering Å, et al. Individual factors associated with neck disability in patients with cervical radiculopathy scheduled for surgery: a study on physical impairments, psychosocial factors, and lifestyle habits Eur Spine J 2014;23:599-605.

19. Thomeé P, Währborg P, Börjesson M, et al. A new instrument for measuring self-efficacy in patients with an anterior cruciate ligament injury. Scand J Med Sci Sports 2006;16:181-87.

20. Kori S, Miller R, Todd D. Kinesiophobia: A new view of chronic pain behaviour. Pain Manag 1990;3:3543.

21. Kvist J, Ek A, Sporrstedt K, et al. Fear of re-injury: A hindrance for returning to sports after anterior cruciate ligament reconstruction. Knee Surg Sports Traumatol Arthrosc 2005;13:393-97.

22. Webster K, Feller J, Lambros C. Development and preliminary validation of a scale to measure the psychological impact of returning to sport following anterior cruciate ligament reconstruction surgery. Phys Ther Sport 2008;9:9-15.

23. Wallston K, Stein M, Smith C. Form C of the MHLC Scales: A condition-specific measure of locus of control. J Pers Assess 1994;63:534-53.

24. Mohtadi N. Development and preliminary validation of the quality of life outcome measure (questionnaire) for chronic anterior cruciate ligament deficiency. Am J Sports Med 1998;26:350-59.

25. Roos E, Roos H, Lohmander L, et al. Knee Injury and Osteoarthritis Outcome Score (KOOS)--development of a self-administered outcome measure. J Orthop Sports Phys Ther 1998;28:88-96.

26. Tabatchnick B, Fidel L. Using Multivariate Statistics. Needham Heights, MA: Allyn \& Bacon, 2001.

27. Røtterud J, Sivertsen E, Forssblad M, et al. Effect of gender and sports on the risk of full-thickness articular cartilage lesions in anterior cruciate ligament injured knees: a nationwide cohort study from Sweden and Norway of 15783 patients. Am J Sports Med 2011;39:1387-94.

28. Bandura A. Self-efficacy: towards a unifying theory of behavior change. Psychol Rev 1977;84:191-215.

29. Benight C, Bandura A. Social cognitive theory of posttraumatic recovery: the role of perceived self-efficacy. Behav Res Ther 2004;42:1129-48.

30. Nyland J, Brand E. Psychological factors in the ACL reconstruction population: are they predictive of patient outcomes? In: Sanchis-Alfonso V, Monllau JC, eds. The ACL-Deficient Knee. London, UK: Springer-Verlag, 2013:189-99.

31. Ivarsson A, Johnson U. Psychological factors as predictors of injuries among senior soccer players. A prospective study. J Sports Sci Med 2010;9:347-52.

32. Ardern C, Taylor N, Feller J, et al. Fifty-five per cent return to competitive sport following anterior cruciate ligament reconstruction surgery: An updated systematic review and meta-analysis including aspects of physical functioning and contextual factors. Br J Sports Med 2014;48:1543-52.

33. Ardern CL. Anterior cruciate ligament reconstruction - not exactly a one-way ticket back to the preinjury level. A review of contextual factors affecting return to sport after surgery. Sports Health 2015;7:22430.

34. Lentz TA, Zeppieri G, George SZ, et al. Comparison of physical impairment, functional, and psychosocial measures based on fear of reinjury/lack of confidence and return-to-sport status after ACL reconstruction. Am J Sports Med 2015;43:345-53.

35. Tjong V, Murnaghan M, Nyhof-Young J, et al. A qualitative investigation of the decision to return to sport after anterior cruciate ligament reconstruction: to play or not to play. Am J Sports Med 2014;42:336-42.

36. Ardern CL, Taylor NF, Feller JA, et al. Sports participation 2 years after anterior cruciate ligament reconstruction in athletes who had not returned to sport at 1 year: a prospective follow-up of physical function and psychological factors in 122 athletes. Am J Sports Med 2015;43:848-56. 
37. Ardern C, Österberg A, Tagesson S, et al. The impact of psychological readiness to return to sport and recreational activities after anterior cruciate ligament reconstruction. Br J Sports Med 2014;bjsports2014-093842.

38. Webster KE, Feller JA, Leigh WB, et al. Younger patients are at increased risk for graft rupture and contralateral injury after anterior cruciate ligament reconstruction. Am J Sports Med 2014;42:641-47.

39. Waldén M. Return to sports after ACL reconstruction surgery: a risk for further joint injury? In: SanchisAlfonso V, Monllau JC, eds. The ACL-deficient knee: a problem solving approach. London: SpringerVerlag, 2013.

40. Øiestad BE, Engebretsen L, Storheim K, et al. Knee osteoarthritis after anterior cruciate ligament injury: a systematic review. Am J Sports Med 2009;37:1434-43.

41. Elwyn G, Dehlendorf C, Epstein RM, et al. Shared decision making and motivational interviewing: achieving patient-centered care across the spectrum of health care problems. Ann Fam Med 2014;12:270-75.

42. Flanigan DC, Everhart JS, Glassman AH. Psychological factors affecting rehabilitation and outcomes following elective orthopaedic surgery. J Am Acad Orthop Surg 2015;23:563-70.

43. Davis JC, Bryan S. Patient reported outcome measures (PROMs) have arrived in sports and exercise medicine: why do they matter? Br J Sports Med 2015;10.1136/bjsports-2014-093707.

44. Culliton S, Bryant D, Overend T, et al. The relationship between expectations and satisfaction in patients undergoing primary total knee arthroplasty. J Arthroplasty 2012;27:490-92.

45. Rea L, Parker R. Designing and conducting survey research: a comprehensive guide. Fourth ed. San Francisco, CA: Jossey-Bass, 2014. 
Table 1. Summary of independent explanatory variables considered for the ordinal regression

\begin{tabular}{|c|c|c|}
\hline & Scale & Construct evaluated \\
\hline $\begin{array}{l}\text { Psychological } \\
\text { factors }\end{array}$ & $\begin{array}{l}\text { Knee-Self-Efficacy Scale (K-SES) }{ }^{19} \\
\text { Tampa Scale for Kinesiophobia (TSK) }{ }^{2021} \\
\text { ACL-Return to Sport after Injury Scale }\end{array}$ & $\begin{array}{l}\text { Knee-related self-efficacy } \\
\text { Fear of re-injury } \\
\text { Psychological readiness to return } \\
\text { to sport/physical activity } \\
\text { Internal locus of control }\end{array}$ \\
\hline $\begin{array}{l}\text { Appraisals of knee } \\
\text { function }\end{array}$ & $\begin{array}{l}\text { ACL-Quality of Life scale }{ }^{24} \\
\text { Knee Injury \& Osteoarthritis Outcome Scale }{ }^{25}\end{array}$ & $\begin{array}{l}\text { Knee-related quality of life } \\
\text { Symptoms } \\
\text { Pain } \\
\text { Activities of daily living } \\
\text { Function in sport/recreation } \\
\text { Quality of life }\end{array}$ \\
\hline $\begin{array}{l}\text { Return to pre-injury } \\
\text { activity }\end{array}$ & $\begin{array}{l}\text { "Have you returned to the same physical activity } \\
\text { as before your injury?" (yes/no) }\end{array}$ & \\
\hline
\end{tabular}


Table 2. Satisfaction with knee function at an average of 3 years after ACL reconstruction based on participants' response to the question "If you were to spend the rest of your life with your knee function just the way it has been in the last week, would you feel..."

\begin{tabular}{llll}
\hline Group & Response to primary outcome & $\boldsymbol{n}$ & $\mathbf{\%}$ \\
\hline Satisfied group & Happy & 32 & 19 \\
& Satisfied & 42 & 25 \\
Mostly satisfied group & Mostly satisfied & 49 & 29 \\
Dissatisfied group & Mixed feelings & 22 & 13 \\
& Mostly dissatisfied & 7 & 4 \\
& Dissatisfied & 9 & 5 \\
& Unhappy & 9 & 5 \\
\cline { 3 - 4 } & & 170 & 100 \\
\hline
\end{tabular}


Table 3. Between-group comparison of demographic, psychological factors, self-reported knee function, and return to pre-injury physical activity data

\begin{tabular}{|c|c|c|c|c|}
\hline \multirow[b]{2}{*}{ Variable } & \multicolumn{3}{|c|}{ Satisfaction with knee function } & \multirow[t]{2}{*}{$P$} \\
\hline & $\begin{array}{l}\text { Satisfied } \\
(n=74)\end{array}$ & $\begin{array}{l}\text { Mostly satisfied } \\
(n=49)\end{array}$ & $\begin{array}{l}\text { Dissatisfied } \\
(n=47)\end{array}$ & \\
\hline $\begin{array}{l}\text { Time from surgery to follow up, months, } \\
\text { mean }(95 \% C I)\end{array}$ & $41.0(37.6-44.4)^{\dagger \S}$ & $31.3(27.2-35.5)$ & $32.1(28.9-36.3)$ & 0.001 \\
\hline Age at follow up, mean $(95 \% C I)$ & $29.6(27.8-31.5)^{\S}$ & $28.9(26.5-31.1)$ & $26.0(23.6-28.3)$ & 0.04 \\
\hline $\begin{array}{ll}\text { Sex } & \\
& \text { Male, } n(\%) \\
& \text { Female, } n(\%)\end{array}$ & $\begin{array}{l}43(58) \\
31(42)\end{array}$ & $\begin{array}{l}26(53) \\
23(47)\end{array}$ & $\begin{array}{l}31(66) \\
16(34)\end{array}$ & 0.43 \\
\hline $\begin{array}{l}\text { Pre-injury physical activity level } \\
\text { Elite, } n(\%) \\
\text { Competitive, } n(\%) \\
\text { Recreational, } n(\%)\end{array}$ & $\begin{array}{l}7(10) \\
47(64) \\
19(26)\end{array}$ & $\begin{array}{l}7(15) \\
28(58) \\
13(27)\end{array}$ & $\begin{array}{l}8(36) \\
31(29) \\
8(19)\end{array}$ & 0.58 \\
\hline \multicolumn{5}{|l|}{ Psychological factors } \\
\hline TSK (17-68), mean $(95 \% C I)$ & $31.1(29.4-32.8)^{\dagger \S}$ & $35.2(33.2-37.2)^{\ddagger}$ & $41.7(39-7-43.7)$ & $<0.001$ \\
\hline ACL-RSI (1-10), mean $(95 \% C I)$ & $6.2(5.8-6.7)^{\dagger \S}$ & $4.7(4.1-5.2)^{*}$ & $3.3(2.8-3.9)$ & $<0.001$ \\
\hline MHLC_internal (6-36), mean $(95 \% C I)$ & $27.5(26.1-28.9)^{\S}$ & $25.7(24.0-27.4)$ & $23.2(21.5-24.9)$ & 0.001 \\
\hline \multicolumn{5}{|l|}{ Appraisal of knee function } \\
\hline ACL-QoL (1-10), mean $(95 \% C I)$ & $8.0(7.7-8.4)^{\dagger \S}$ & $6.3(5.9-6.8)^{\ddagger}$ & $4.4(4.0-4.8)$ & $<0.001$ \\
\hline KOOS_symptoms $(0-100)$, mean $(95 \%$ CI) & $86.5(82.6-90.5)^{\dagger \S}$ & $78.7(73.9-83.4)^{\ddagger}$ & $62.0(57.3-66.6)$ & $<0.001$ \\
\hline KOOS_pain (0-100), mean $(95 \% C I)$ & $93.9(90.6-97.2)^{\dagger \S}$ & $86.0(82.1-89.9)^{\ddagger}$ & $73.1(69.3-77.0)$ & $<0.001$ \\
\hline KOOS_ADL $(0-100)$, mean $(95 \% C I)$ & $98.1(95.0-100.0)^{\dagger \S}$ & $93.2(89.4-97.0)^{\ddagger}$ & $80.7(76.9-84.4)$ & $<0.001$ \\
\hline KOOS_sport (0-100), mean $(95 \% C I)$ & $85.8(80.7-90.9)^{\dagger \S}$ & $69.6(63.6-75.78)^{\ddagger}$ & $48.4(42.4-54.4)$ & $<0.001$ \\
\hline KOOS_QoL $(0-100)$, mean $(95 \% C I)$ & $78.2(73.8-82.6)^{\dagger \S}$ & $60.9(55.6-66.2)^{\ddagger}$ & $40.6(34.2-47.0)$ & $<0.001$ \\
\hline $\begin{array}{l}\text { Returned to pre-injury physical activity }^{b} \\
\text { Yes, } n(\%) \\
\text { No, } n(\%)\end{array}$ & $\begin{array}{l}44(61)^{\dagger \S} \\
28(39)^{\dagger \S}\end{array}$ & $\begin{array}{l}14(29) \\
34(71)\end{array}$ & $\begin{array}{l}10(22) \\
35(78)\end{array}$ & $<0.001$ \\
\hline
\end{tabular}

${ }^{a}$ Missing data for 1 participant in each of the satisfied and mostly satisfied groups, ${ }^{b}$ Missing data for 5 participants; † $\uparrow$ significant difference between satisfied and mostly satisfied groups, ${ }^{\$}$ significant difference between satisfied and dissatisfied groups, "'significant difference between mostly satisfied and dissatisfied group; 95\% CI, 95\% confidence interval; K-SES, Knee Self-Efficacy Scale; TSK, Tampa Scale for Kinesiophobia; ACL-RSI, ACL-Return to Sport after Injury scale; MHLC_internal, Multidimensional Health Locus of Control scale internal items; ACL-QoL, ACL-Quality of life scale; KOOS, Knee Osteoarthritis Outcome Scale. Possible score range for each independent explanatory variable indicated in parentheses. 
Table 4. Ordinal regression model of the relationship between satisfaction with knee function after $\mathrm{ACL}$ reconstruction, and psychological factors and self-reported knee function

\begin{tabular}{lrrrrr}
\hline Variable & Estimate & S.E. & Wald statistic & $P$ & Odds ratio, 95\% CI \\
\hline K-SES (0-10) & 0.41 & 0.15 & 6.97 & 0.008 & $1.50,1.11-2.03$ \\
KOOS_symptoms (0-100) & 0.03 & 0.02 & 3.05 & 0.08 & $1.03,0.99-1.05$ \\
KOOS_QoL (0-100) & 0.05 & 0.02 & 9.66 & 0.002 & $1.05,1.02-1.08$ \\
Returned to pre-injury activity (No) & 1.11 & 0.40 & 7.66 & 0.006 & $3.30,1.51-7.24$ \\
Age & 0.19 & 0.02 & 0.62 & 0.43 & $1.02,0.97-2.03$ \\
Time to follow-up & 0.02 & 0.02 & 1.99 & 0.16 & $1.02,0.99-1.04$ \\
Sex (male) & -0.19 & 0.38 & 0.23 & 0.63 & $0.83,0.39-1.75$ \\
\hline
\end{tabular}

Note KOOS, Knee Osteoarthritis Outcome Score; QoL, quality of life; K-SES, Knee Self-Efficacy Scale; age was dichotomised to 18-26 years and 27-45 years; possible score ranges for continuous variables shown in parentheses; reference group for dichotomous variables shown in parentheses. 


\section{Figure legend}

Figure 1. Participant identification

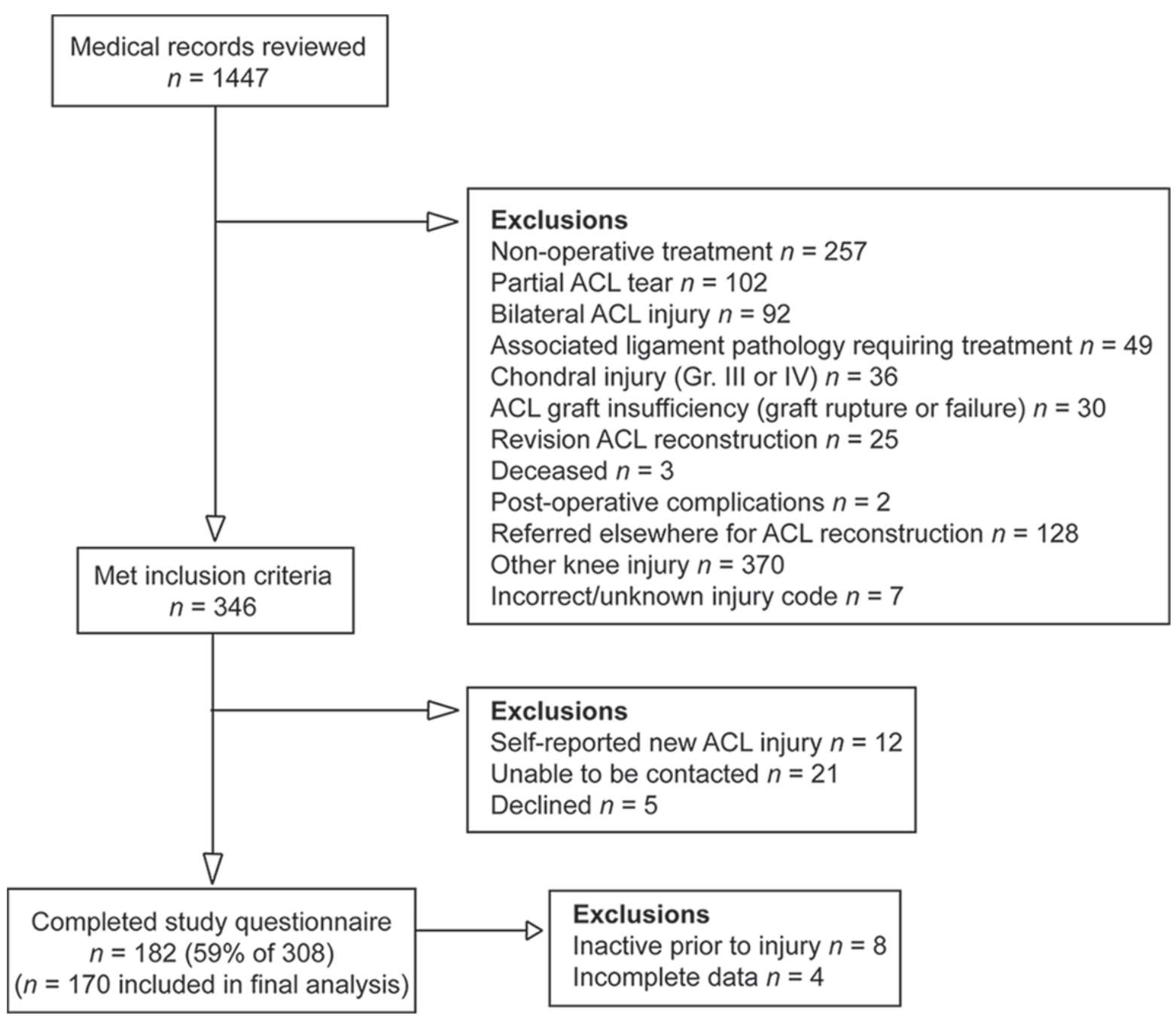


Description of patient-reported outcome measures

\begin{tabular}{|c|c|c|}
\hline Outcome measure & Description and scoring & Measurement properties \\
\hline $\begin{array}{l}\text { Knee Self-efficacy Scale } \\
\text { (K-SES) }{ }^{1}\end{array}$ & $\begin{array}{l}\text { Twenty-two items evaluating self-efficacy for current (e.g. "How } \\
\text { certain are you about jumping sideways from one leg to the other?") } \\
\text { and future knee function (e.g. "How certain are you that your knee will } \\
\text { not get worse than before surgery?"). } \\
\text { Possible scores range from } 0 \text { to } 10 \text {. } \\
\text { A higher score indicates higher self-efficacy. }\end{array}$ & $\begin{array}{l}\text { High internal consistency (Cronbach's } \alpha: 0.78 \text { to } 0.94)^{1} \\
\text { Good test re-test reliability (ICC }=0.75)^{1} \\
\text { Evidence of construct validity demonstrated by low correlation } \\
\text { with MHLC-C }(r-0.18 \text { to } 0.03) \text { and KOOS }(r-0.11 \text { to } 0.25)^{1} \text {, and } \\
\text { high correlation with ACL-RSI }(r 0.71) .^{2}\end{array}$ \\
\hline $\begin{array}{l}\text { Multi-dimensional Health } \\
\text { Locus of Control C-form } \\
\text { (MHLC-C) }\end{array}$ & $\begin{array}{l}\text { Twenty-four items across four domains - Internal ( } 8 \text { items), Chance ( } 8 \\
\text { items), Doctors ( } 4 \text { items), Others ( } 4 \text { items). } \\
\text { Possible scores for the Internal and Chance domains range from } 6 \text { to } \\
\text { 36, and for Doctors and Others domains range from } 6 \text { to } 18 \text {. } \\
\text { For all domains, a higher score indicates a stronger contribution to the } \\
\text { overall health locus of control. }\end{array}$ & $\begin{array}{l}\text { Evidence of known-groups validity: } \\
\text { After ACL reconstruction, people with high internal health locus of } \\
\text { control had higher sports activity level, and better self-reported } \\
\text { knee function than people with low internal health locus of } \\
\text { control. } \\
\text { People with lower perceived functional limitations before ACL } \\
\text { reconstruction had a more internal health locus of control. } \\
\text { More internal health locus of control associated with greater } \\
\text { psychological readiness to return to sport measured with ACL- }^{5} \\
\text { RSI. }{ }^{2}\end{array}$ \\
\hline $\begin{array}{l}\text { Anterior Cruciate } \\
\text { Ligament-Return to Sport } \\
\text { after Injury scale (ACL- } \\
\text { RSI) }\end{array}$ & $\begin{array}{l}\text { Twelve items assessing confidence, emotions, and risk appraisal } \\
\text { related to returning to activity after ACL reconstruction (e.g. "Are you } \\
\text { confident that you can perform at your previous level of sports } \\
\text { participation?"). } \\
\text { Possible scores range from } 1 \text { to } 10 \text {. } \\
\text { A higher score indicates greater psychological readiness to return to } \\
\text { activity. }\end{array}$ & $\begin{array}{l}\text { High internal consistency (Cronbach's } \alpha 0.95)^{2} \\
\text { High reproducibility (ICC } 0.89)^{2} \\
\text { Evidence of known-groups validity (scores discriminated between } \\
\text { people who did and did not return to preinjury physical activity } \\
\text { after ACL reconstruction (Ardern et. al. 2013; Kvist et. al. 2013; } \\
\text { Webster et. al. 2008)., }{ }^{2,6,7}\end{array}$ \\
\hline $\begin{array}{l}\text { Tampa Scale for } \\
\text { Kinesiophobia (TSK) }\end{array}$ & $\begin{array}{l}\text { Seventeen items evaluating fear of injury due to movement and } \\
\text { physical activity (e.g. "My injury has put my knee at risk for the rest of } \\
\text { my life"). } \\
\text { Possible scores range from } 17 \text { to } 68 \text {. } \\
\text { A higher score indicates greater fear of re-injury. }\end{array}$ & $\begin{array}{l}\text { Evidence of known-groups validity (scores discriminated between } \\
\text { people who did and did not return to preinjury sport after ACL } \\
\text { reconstruction). }{ }^{7,8}\end{array}$ \\
\hline
\end{tabular}




\begin{tabular}{|c|c|c|}
\hline Outcome measure & Description and scoring & Measurement properties \\
\hline \multirow{11}{*}{$\begin{array}{l}\text { Knee Injury and } \\
\text { Osteoarthritis Outcome } \\
\text { Score (KOOS) }\end{array}$} & Symptoms Domain & High test re-test reliability (ICC 0.83 to 0.95$)^{10}$ \\
\hline & $\begin{array}{l}\text { Seven items that assess the frequency of symptoms including swelling } \\
\text { and knee stiffness. } \\
\text { Possible scores range from } 0 \text { to } 100 . \\
\text { A higher score indicates less frequent knee symptoms. }\end{array}$ & Low to moderate internal consistency (Cronbach's $\alpha 0.25$ to 0.75$)^{10}$ \\
\hline & Pain Domain & High test re-test reliability (ICC 0.85 to 0.93 ). ${ }^{10}$ \\
\hline & $\begin{array}{l}\text { Nine items that assess the frequency and amount of pain experienced } \\
\text { during tasks including straightening the knee, walking, and sitting. } \\
\text { Possible scores range from } 0 \text { to } 100 \text {. } \\
\text { A higher score indicates less pain. }\end{array}$ & High internal consistency (Cronbach's $\alpha 0.84$ to 0.91$)^{10}$ \\
\hline & Activities of daily living domain & Moderate to high test re-test reliability (ICC 0.75 to 0.91$)^{10}$ \\
\hline & $\begin{array}{l}\text { Seventeen items that assess the degree of difficulty in completing daily } \\
\text { activities in the preceding week. } \\
\text { Possible scores range from } 0 \text { to } 100 \text {. } \\
\text { A higher score indicates a less difficulty with daily activities. }\end{array}$ & High internal consistency (Cronbach's $\alpha 0.94$ to 0.95$)^{10}$ \\
\hline & Sport Domain & High internal consistency (Cronbach's $\alpha 0.85$ to 0.89 ). ${ }^{10}$ \\
\hline & Five items that assess functioning in activities including squatting, & Moderate to high test re-test reliability (ICC 0.61 to 0.89 ). ${ }^{10}$ \\
\hline & $\begin{array}{l}\text { running, and jumping. } \\
\text { Possible scores range from } 0 \text { to } 100 \text {. } \\
\text { A higher score indicates better function in sport and recreational } \\
\text { activities. }\end{array}$ & $\begin{array}{l}\text { Convergent and divergent validity demonstrated for all KOOS } \\
\text { domains }{ }^{10}\end{array}$ \\
\hline & Quality of Life Domain & High test re-test reliability (ICC 0.83 to 0.95 ). ${ }^{10}$ \\
\hline & $\begin{array}{l}\text { Four items that assess the impact of a knee injury on daily functioning. } \\
\text { Possible scores range from } 0 \text { to } 100 \text {. } \\
\text { A higher score indicates a higher knee-related quality of life. }\end{array}$ & $\begin{array}{l}\text { Moderate to high internal consistency (Cronbach's } \alpha 0.64 \text { to } \\
0.90)^{10}\end{array}$ \\
\hline \multirow{4}{*}{$\begin{array}{l}\text { Anterior Cruciate } \\
\text { Ligament-Quality of Life } \\
\text { scale (ACL-QoL) }\end{array}$} & \multirow{4}{*}{$\begin{array}{l}\text { Thirty-two item scale evaluating quality of life in relation to symptoms } \\
\text { and physical complaints, work-related concerns, recreational activities } \\
\text { and sports participation, lifestyle, and social and emotional functioning. } \\
\text { Possible scores range from } 1 \text { to } 10 \text {. } \\
\text { A higher score indicates a higher knee-related quality of life. }\end{array}$} & Average error in test re-test reliability of $6 \%^{11}$ \\
\hline & & $\begin{array}{l}\text { Content validity demonstrated by at least } 80 \% \text { agreement by expert } \\
\text { orthopaedic surgeons on all questions }{ }^{11}\end{array}$ \\
\hline & & $\begin{array}{l}\text { Appropriate responsiveness to change demonstrated, based on } \\
\text { change in clinical condition }{ }^{11}\end{array}$ \\
\hline & & $\begin{array}{l}\text { Strong correlation with ACL-RSI ( } r \text { 0.82) demonstrating evidence } \\
\text { of construct validity }^{2}\end{array}$ \\
\hline
\end{tabular}

Note. Swedish-language versions of all outcome measures were used. 


\section{References}

1. Thomeé P, Währborg P, Börjesson M, et. al. A new instrument for measuring self-efficacy in patients with an anterior cruciate ligament injury. Scand J Med Sci Sports 2006;16:181-7.

2. Kvist J, Österberg A, Gauffin H, et. al. Translation and measurement properties of the Swedish version of ACL-Return to Sports after Injury questionnaire. Scand J Med Sci Sports 2013;23:56875 .

3. Wallston K, Stein M, Smith C. Form C of the MHLC Scales: A condition-specific measure of locus of control. J Pers Assess 1994;63:534-53.

4. Nyland J, Cottrell B, Harreld K, et. al. Self-reported outcomes after anterior cruciate ligament reconstruction: An internal health locus of control score comparison. Arthroscopy 2006;22:122532.

5. Nyland J, Johnson D, Caborn D, et. al. Internal health status belief and lower perceived functional deficit are related among anterior cruciate ligament-deficient patients. Arthroscopy 2002;18:5158.

6. Webster K, Feller J, Lambros C. Development and preliminary validation of a scale to measure the psychological impact of returning to sport following anterior cruciate ligament reconstruction surgery. Phys Ther Sport 2008;9:9-15.

7. Ardern C, Taylor N, Feller J, et. al. A systematic review of the psychological factors associated with returning to sport following injury. Br J Sports Med 2013;47:1120-6.

8. Kori S, Miller R, Todd D. Kinesiophobia: A new view of chronic pain behaviour. Pain Manag 1990;3:35-43.

9. Roos E, Roos H, Lohmander L, et. al. Knee Injury and Osteoarthritis Outcome Score (KOOS)-development of a self-administered outcome measure. J Orthop Sports Phys Ther 1998;28:88-96.

10. Collins N, Misra D, Felson D, et. al. Measures of knee function. Arthritis Care Res 2011;63:S208-S28.

11. Mohtadi N. Development and validation of the quality of life outcome measure (questionnaire) for chronic anterior cruciate ligament deficiency. Am J Sports Med 1998;26:350-9. 
To determine the explanatory variables to be included in the final model, a two-stage, stepwise process was used. In the first stage, separate ordinal regression models, with each explanatory variable entered individually, were completed. In each model, age, sex, and time to follow up were included as adjusting variables to account for potential confounding. A Variance Inflation Factor (VIF) of $>5$ was used to indicate significant multicollinearity, and explanatory variables with significant multicollinearity were excluded from the regression analysis. The ACL-QoL and KOOS pain variables were excluded due to significant multicollinearity. A significance level of $<0.05$ was used to decide whether individual explanatory variables were retained for the second stage of the analysis. The results of the individual regression models are reported in the table.

In the second stage, all explanatory variables meeting the statistical criterion for inclusion in the final model were entered into an ordinal regression model. The overfitted model was then reduced by eliminating one variable at a time based on the Wald statistic and a significance value of $<0.1$. Variables reaching significance were automatically retained, and among the variables not reaching significance, the variable with the lowest Wald statistic was removed. The backward stepwise process continued until no further variables were excluded, resulting in the set of independent explanatory variables to be included in the final model.

Table. Results of the individual regression models (adjusted for age, sex and time to follow-up) used to determine the independent explanatory variables to be included in the final model

\begin{tabular}{lrrrrr}
\hline Variable & Estimate & S.E. & Wald statistic & $P$ & Odds ratio, 95\% CI \\
\hline K-SES & 0.75 & 0.10 & 52.5 & $<0.0001$ & $2.18,1.73-2.60$ \\
TSK & -0.16 & 0.03 & 37.3 & $<0.0001$ & $0.85,0.81-0.90$ \\
ACL-RSI & 0.58 & 0.10 & 43.4 & $<0.0001$ & $1.79,1.51-2.13$ \\
MHLC_internal & 0.10 & 0.03 & 11.6 & 0.001 & $1.10,1.04-1.17$ \\
& & & & & \\
ACL-QoL & 1.07 & 0.13 & 66.1 & $<0.0001$ & $2.92,2.26-3.78$ \\
KOOS_symptom & 0.08 & 0.01 & 42.8 & $<0.0001$ & $1.08,1.05-1.10$ \\
KOOS_pain & 0.10 & 0.02 & 37.5 & $<0.0001$ & $1.11,1.07-1.14$ \\
KOOS_ADL & 0.12 & 0.02 & 28.0 & $<0.0001$ & $1.12,1.08-1.17$ \\
KOOS_sport & 0.06 & 0.01 & 49.4 & $<0.0001$ & $1.06,1.04-1.08$ \\
KOOS_QoL & 0.09 & 0.02 & 59.7 & $<0.0001$ & $1.10,1.07-1.12$ \\
& \multicolumn{5}{c}{1.7 .1} \\
Returned to pre-injury activity & 1.33 & 0.32 & & $<0.0001$ & $2.64,1.41-4.97$ \\
\hline Note K-SES, Knee Self-Efficacy Scale; MHLC, Multidimensional Health Locus of Control; ACL-RSI, ACL- \\
Return to Sport after Injury scale; TSK, Tampa Scale for Kinesiophobia; KOOS, Knee Osteoarthritis Outcome \\
Score; ACL-QoL, ACL-Quality of Life scale
\end{tabular}

